FERNÁNDEZ CORNAGO, M., «La retroactividad de la declaración de nulidad de las cláusulas abusivas», REDUR I3,

diciembre 2015, págs. 249-268. ISSN I695-078X

\title{
LA RETROACTIVIDAD DE LA DECLARACIÓN DE NULIDAD DE LAS CLÁUSULAS ABUSIVAS
}

\author{
Marta FERNÁNDEZ CORNAGO \\ GRADUADA EN DERECHO \\ UNIVERSIDAD DE LA RIOJA
}

SUMARIO: I. Introducción. II. La falta de transparencia en las cláusulas suelo. II.I. Cláusulas suelo: concepto y normativa aplicable. II.2. Cláusulas referidas al objeto principal del contrato. II.3. El doble control de transparencia consagrado por el TS. III. La declaración de nulidad de las cláusulas abusivas. III. I. Efectos de la declaración de nulidad. III.2. El problema de la retroactividad de la declaración de nulidad de las cláusulas suelo. III.2.I. Sistema de fuentes y primacía de la ley. III.2.I.I. La jurisprudencia como fuente complementaria en nuestro ordenamiento jurídico. III.2.I.2. El imperio de la ley sobre los principios generales del Derecho. III.2.2. Diferenciación entre acciones individuales y colectivas. III.2.2.I. Respecto de la inexistencia de cosa juzgada. III.2.2.2. Respecto del orden público económico. III.2.3. La figura de la ineficacia contractual. III.2.3.I. Ineficacia contractual derivada de actos y negocios jurídicos. III.2.3.2. Ineficacia contractual en relación con la diferenciación entre retroactividad de la nulidad y retroactividad de la sentencia. III.2.3.3. Ineficacia derivada de acciones de impugnación en relación con el efecto restitutorio y alcance ex tunc. III.2.4. Prohibición de moderar la nulidad de las cláusulas abusivas. III.2.4.I. Respecto de la vulneración del «principio de no vinculación». III.2.4.2. Respecto de la buena fe como principio configurador de los deberes del predisponente. III.2.4.3. Respecto del efecto disuasorio de la ineficacia de las cláusulas abusivas.

RESUMEN: La esencia del presente trabajo está constituida por el análisis sustantivo de la diversidad de criterios que mantienen los tribunales acerca de los efectos de la declaración de nulidad de las cláusulas suelo abusivas por falta de transparencia. Para ello, se hace necesario abordar primeramente el doble control de transparencia como doctrina jurisprudencial consagrada por nuestro Alto Tribunal. Posteriormente ahondaré en el problema de la retroactividad y, por ende, en lo relativo a la devolución de las cantidades indebidamente cobradas por aplicación de dichas cláusulas. En esta cuestión cobra importancia el pronunciamiento del TS acerca de la mal llamada irretroactividad y la crítica a éste por alejarse de la ley basando su decisión en razones más económicas que jurídicas.

Palabras Clave: cláusula suelo, doble control de transparencia, declaración de nulidad, retroactividad, devolución de cantidades.

ABSTRACT: The objective of this essay is to analyze the diversity of views that courts hold about the effects of abusive ground clauses' declaration of nullity due to the lack of transparency. At first, it is necessary to provide the dual control of transparency as case law established by the High Court. Then, I will delve into the problem of the retroactivity; therefore, I will examine the refund of the wrongful amounts because of the aplication of those clauses. About this question, it is important to point out the so-called non retroactivity and the criticism to the court for get away of the law basing his decision on economical reasons instead of juridic reasons.

KEYWORDS: ground clause, dual control of transparency, declaration of nullity, retroactivity, return of amounts. 


\section{Introducción}

El tema objeto de estudio en el presente trabajo es de una importancia indudable, debido al protagonismo que ha cobrado desde un tiempo a esta parte, reflejado en el aumento del número de controversias surgidas alrededor de las cláusulas abusivas. En el ámbito bancario, ha sido frecuente incluir en los contratos de préstamo hipotecario cláusulas limitativas de los intereses a pagar por el prestatario. Dichas cláusulas pueden presentar límites máximos -cláusulas techo- y límites mínimos -cláusulas suelo-. Estas últimas, las denominadas cláusulas suelo, pueden definirse como aquellas estipulaciones que, atendiendo a los cambios fluctuantes que pueden afectarle, limitan el tipo de interés de referencia aplicable ${ }^{\mathrm{I}}$-generalmente el Euribor-. De esta manera, se producen situaciones en las que el prestatario no se verá beneficiado por los descensos del tipo de interés de referencia que se encuentren por debajo del pactado en la cláusula limitativa de interés mínimo.

A pesar de los avances producidos en la normativa protectora de los consumidores, se han dado innumerables casos de abuso por parte de las entidades bancarias. Prueba de ello es el alto número de hipotecas que se venían firmando en los últimos años en las que se insertaban dichas cláusulas suelo. De este modo, la importancia del tema queda reflejada tanto en el altísimo número de decisiones judiciales dictadas al respecto, como en las sucesivas reformas legislativas por las que ha atravesado la cuestión en los últimos años, como luego analizaré.

Para abordar esta materia, he optado por diferenciar dos grandes bloques. En el primero de ellos, explicaré en qué consiste la falta de transparencia como criterio para declarar la nulidad por abusivas de determinadas cláusulas suelo. Y en el segundo bloque, he analizado la nulidad de dichas cláusulas y los efectos de tal declaración, y, con más profundidad, las controversias surgidas en torno al problema de la limitación de la retroactividad y, por ende, la no restitución íntegra de cantidades.

Dicha cuestión acerca de la retroactividad de la declaración de nulidad de estas cláusulas constituye la esencia del presente trabajo. En su estructura se pueden diferenciar dos grandes bloques, siendo, la pieza importante del mismo el segundo bloque, como ya he dicho. Primeramente, explicaré en qué consiste la falta de transparencia como criterio fijado por el Supremo para declarar la nulidad por abusivas de determinadas cláusulas suelo. En segundo lugar analizaré la nulidad de dichas cláusulas y los efectos de esta declaración, y, con más profundidad las controversias surgidas en torno al problema de la limitación de retroactividad y la no restitución íntegra de cantidades. A este respecto, cobra especial la STS de 9 de mayo de 2013

\section{La falta de transparencia en las cláusulas suelo}

\section{II.I. Cláusulas suelo: concepto y normativa aplicable}

Las escrituras de préstamo hipotecario pueden incorporar límites a la variación de los tipos de interés o índices de referencia. Si tal acotación es a la baja, la cláusula fijará un tipo de interés que actuará como suelo del tipo pactado, con lo que se garantizan unos

${ }^{\mathrm{I}}$ Moreno García, L., Cláusulas suelo y control de transparencia: tratamiento sustantivo y procesal, Marcial Pons, Madrid, 2015, pág. 49 . 
ingresos mínimos para la entidad que concede el crédito, sea cual sea la coyuntura de tipos en los mercados ${ }^{2}$.

Cuando en dichas cláusulas quedan insertos límites mínimos a las eventuales oscilaciones del interés de referencia ${ }^{3}$, se denominan cláusulas suelo. Según datos del Banco de España, el 97\% de los préstamos hipotecarios concedidos en nuestro país son a tipo variable, y, de ellos, un tercio aproximadamente, contiene la citada cláusula4.

Generalmente, el interés de referencia ha sido el Euribor, por lo que fue desde 2002 cuando dichas cláusulas han cobrado virtualidad, debido a que a partir de dicha fecha, el Euribor comenzó a reducirse, partiendo desde un 3,5\% en enero de dicho año, hasta situarse en el 2,9\% en diciembre, para, con excepción del periodo comprendido entre enero de 2007 hasta noviembre de 2008 , permanecer por debajo del $4 \%$. Estas estipulaciones han abierto debate durante los últimos años acerca de su licitud, ante la posibilidad de ser declaradas abusivas debido a la imposibilidad de los prestatarios de verse beneficiados por las bajadas de los tipos de interés derivados de la crisis económica vivida en España.

Dichas cláusulas suelo se hallan previstas expresamente en la normativa de transparencia, la cual, en palabras de GONZÁLEZ CARRASCO, regula la información que «deben incorporar los instrumentos de cobertura del riesgo de tipo de interés en los préstamos hipotecarios a tipo variable» ${ }^{6}$. Son por tanto lícitas conforme a la Orden EHA/2899/20II, de 28 de octubre, de transparencia y protección del cliente de servicios bancarios ${ }^{7}$, derogadora de la Orden Ministerial de 5 de mayo de I994, sobre transparencia de las condiciones financieras de los préstamos hipotecarios ${ }^{8}$, y conforme a la Directiva 20I4/I7/UE del Parlamento Europeo y del Consejo, de 4 de febrero, sobre los contratos de crédito celebrados con los consumidores para bienes inmuebles de uso residencial. El Banco de España en su Informe de 27 de abril de 2010 reconoce también la licitud de este tipo de cláusulas9.

De este modo, dichas cláusulas serán lícitas siempre y cuando se ajusten a las exigencias normativamente establecidas, y según jurisprudencia sentada por el Tribunal Supremo desde el 9 de mayo de 2013 , siempre y cuando se ajusten al doble control de transparencia. De esta forma por tanto, su licitud queda condicionada por el deber de las entidades bancarias de informar al cliente de manera que éste, antes y en el momento de firmar el contrato, conociera la existencia de estas cláusulas y el efecto que podrían ocasionar sobre el coste real del crédito, de tal modo que adopte la decisión de contratar con

\footnotetext{
${ }^{2}$ Informe del Banco de España, BOCG $n^{\circ} 457$, de 7 de mayo de 20ıо, pág. I3.

${ }^{3}$ Moreno García, L., op. cit., pág. 49.

${ }^{4}$ LÓPEZ JIMÉNEZ. J.M., «La cláusula suelo en los préstamos hipotecarios: una discusión abierta para el debate» Diario La Ley $n^{\circ}$ 8279, 2014.

${ }^{5}$ Cadenas de Gea, C., Pareja Marina, S.M, Casasola Díaz, J.M, «Cláusula suelo en préstamos hipotecarios: mire bien por dónde pisa» eXtoikos $n^{\circ}$ 9, 2013, pág. 27.

${ }^{6}$ González Carrasco, M.C., «Requisitos sobre la validez de las cláusulas suelo y consecuencias de la nulidad acordada por la STS de 9 de mayo de 20I3» Revista CESCO de Derecho de Consumo n 6, 20I3, pág. I20.

${ }^{7} B O E \mathrm{n}^{\circ} .26 \mathrm{I}$, de 29 de octubre de 20II, págs. II3242-II3283.

${ }^{8} B O E \mathrm{n}^{\circ}$. II2, de II de mayo de I994, págs. I4444-I4449.

${ }^{9}$ Informe del Banco de España, loc.cit., pág. I4.
} 
pleno conocimiento de causa ${ }^{\mathrm{Io}}$. Es decir, su eficacia dependerá de la información dada por el predisponente y la libre formación de la voluntad del prestatario. A este respecto, el TS se inclina por considerar que las cláusulas suelo son sospechosamente nulas per se, ignorando la licitud que le otorga la normativa vigente ${ }^{\mathrm{II}}$.

El Supremo, con la sentencia de 9 de mayo de 20I3, siguiendo su propia línea jurisprudencial, consagra el reconocimiento de los rasgos de contractualidad, predisposición, imposición y generalidad de dichas cláusulas ${ }^{\mathrm{I} 2}$. Estos se pueden extraer del art. I de la Ley 7/1998 de condiciones generales de la contratación ${ }^{\text {13 }}$, siendo por tanto de aplicación a las cláusulas objeto de estudio de este trabajo la citada ley. Los contratos a los que se incorporan las condiciones generales son denominados contratos de adhesión, aquellos pre redactados por una de las partes -la entidad bancaria- limitándose la otra parte - el consumidor- a aceptar o rechazar el contrato en su integridad.

\section{II.2. Cláusulas referidas al objeto principal del contrato}

Cuestión debatida ha sido la consideración de estas condiciones generales como referidas al objeto principal del contrato. A este respecto, el art. 4.2 de la Directiva 93/13/CEE ${ }^{14}$ - que no fue traspuesta por España, según CÁMARA LAPUENTE por un lapsus en el trámite parlamentario ${ }^{15}$ - prevé expresamente la prohibición de control judicial como abusivas de las cláusulas relativas al objeto principal del contrato.

El TS debió decidir sobre si aplicar o no la prohibición del control de abusividad a las cláusulas suelo. En este sentido, entiende que las cláusulas suelo sí están referidas al objeto principal del contrato. Así, considera por tanto dichas cláusulas no susceptibles de quedar sometidas a un control de equilibrio de prestaciones como ocurría en la SJM Sevilla 30 septiembre 20I0, antecedente del asunto que llega al Supremo. La STS 9 mayo 20I3, teniendo presente lo dispuesto por la Directiva comunitaria, declara la imposibilidad del control judicial de las cláusulas referidas al objeto principal del contrato, salvo que aquéllas no estén redactadas con la debida transparencia ${ }^{\mathrm{I} 6}$.

De esta forma, soluciona los problemas sometiendo dichas cláusulas a un control de transparencia y no de contenido ${ }^{\mathrm{r}}$, entendiendo así la posibilidad de declarar nulas las cláusulas suelo cuando no reúnan las exigencias del doble control de transparencia. Es decir, somete a las cláusulas suelo a un control distinto del de contenido, admitiendo la

\footnotetext{
${ }^{10}$ Pertíñez Vílchez, F., «Falta de transparencia y carácter abusivo de la cláusula suelo en los contratos de préstamo hipotecario», Revista para el análisis del Derecho InDret, Barcelona, 20I3, pág. 4.

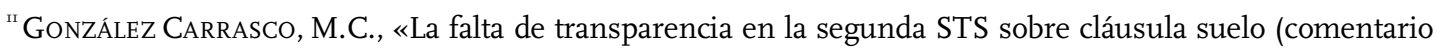
a la STS de 8 de septiembre de 20I4 y a su voto particular)», Centro de Estudios de Consumo, 20I4.

${ }^{12}$ RUIZ DE LARA, M., Condiciones generales de la contratación, cláusulas abusivas y protección del consumidor a la luz de la jurisprudencia comunitaria y nacional, Fe d'erratas, Madrid, 20I4, págs. I7-I8.

${ }^{13}$ BOE nº. 89, de I4 de abril de I998, págs.I2304-I23I4.

${ }^{14}$ Directiva I993/I3/CEE, de 5 de abril, sobre cláusulas abusivas en los contratos celebrados con consumidores (DOUE nº. 95, de 2I de abril de I993, págs.. 29-35).

${ }^{15}$ CÁmARa LAPUente S., «El control de cláusulas abusivas sobre el precio: de la STJUE de 3 junio 20 io (Caja Madrid) a la STS 9 mayo 20I3 sobre cláusulas suelo» Revista Cesco de Derecho de Consumo n6, 2013, pág. IOO.

${ }^{16}$ Cámara Lapuente S., loc. cit., pág. 98.

${ }^{17}$ Moreno García, L., op. cit., pág. 66.
} 
prohibición de este control fijada en el 4.2 de la Directiva, y quedando éstas condiciones generales sujetas a un doble filtro de transparencia.

II.3. El doble control de transparencia consagrado por el TS

El denominado doble control o filtro de transparencia de las cláusulas suelo entendidas como referidas al objeto principal del contrato- comprende un primer control de incorporación, siguiendo las exigencias de transparencia propios de la LCGC, y un segundo control de transparencia en sentido estricto, referido al conocimiento real del prestatario del desarrollo razonable de dichas cláusulas a lo largo del desarrollo del contrato $^{\mathrm{i}}$.

Éste, en palabras de DE TORRE PEREA, se trata de un control adicional previsto para garantizar que el adherente conozca o pueda conocer la carga económica u onerosidad derivada de la ejecución del contrato. No basta con una redacción clara, sin quedar enmascarada $u$ ocultada entre el clausulado contractual sino que se exige un previo y elevado nivel de información ${ }^{\text {I9 }}$.

El control de transparencia encuentra sus orígenes, en palabras de CÁMARA LAPUENTE, en el Derecho alemán -Transparenzgebot-, cuya jurisprudencia comenzaba a enunciarlo con cierto reflejo en el art. 4.2 de la Directiva $93 / 13^{20}$. Y es precisamente este precepto el que sirve de apoyo legal para asentar el control de transparencia en nuestro ordenamiento, cuyo contenido prevé expresamente la prohibición de control judicial por abusivas de las cláusulas referidas al objeto principal del contrato, haciéndose así necesario fijar un control diferente al de contenido.

El TS considera la transparencia real como aquella referida al conocimiento de los consumidores de las consecuencias jurídicas y económicas que conlleva el devenir del contrato, y no a una mera exigencia de claridad y comprensibilidad en su redacción, ya que así debe interpretarse lo dispuesto por la Directiva 93/13. De este modo, como señala CORDERO LOBATO, el Supremo «considera que los contratos cuestionados carecían de la transparencia exigida en el art. 80.I TRLCU, porque no se permite al consumidor identificar la cláusula como definidora del objeto del contrato y conocer el real reparto de riesgos de la variabilidad de los tipos» ${ }^{2 \mathrm{I}}$.

En la jurisprudencia española, la STS 9 mayo 2013 marca un antes y un después en la jurisprudencia española. Algunas de las afirmaciones más importantes enunciadas por dicha sentencia en lo relativo al control de transparencia son las siguientes.

En primer lugar, considera que las cláusulas suelo no son abusivas por sí solas, aún cuando exista desproporción entre el suelo o el techo; ni siquiera cuando no exista techo, ya

\footnotetext{
${ }^{\mathrm{I} 8}$ Cámara Lapuente S., loc cit. pág. I05.

${ }^{19}$ De Torre Perea, J.M., «Nulidad de cláusula suelo por falta de transparencia fundada en una insuficiente información del cliente bancario. En especial, sobre la idoneidad de su impugnación mediante el ejercicio de la acción de cesación», Revista Jurídica Valenciana n. 2, 2014, pág. 3.

${ }^{20}$ CÁmara LAPUente, S., El control de las cláusulas «abusivas» sobre elementos esenciales del contrato, Aranzadi, Cizur Menor, 2006, pág. I24.

${ }^{21}$ CoRdero Lobato, E., «Nulidad de cláusulas suelo no transparentes: ¿puede el consumidor recuperar los pagos excesivos? (STS, Sala de lo Civil, de 9 de mayo de 20I3)» CESCO de Derecho de Consumo n 6, 20I3, pág. I3I.
} 
que la determinación de cuál sea el interés queda a la iniciativa empresarial, dentro de los límites fijados por el legislador. En segundo lugar, entiende que los contratos objeto del control de abusividad no cumplían los deberes de transparencia exigida en el art. 80.I TRLGDCU, al no permitir al consumidor identificar la cláusula suelo como objeto principal del contrato de modo que conociera el correcto devenir del mismo y el reparto de riesgos de la variabilidad de los tipos. Deduce también el TS que la abusividad por falta de transparencia no determina la nulidad del contrato, pero sí la de la cláusula suelo no transparente ${ }^{22}$.

Pues bien, una vez examinado lo anterior, podemos decir que el Supremo, con el pronunciamiento de 9 de mayo de $203^{23}$, y junto con la STS 402/20I2 de I8 de junio ${ }^{24}$, realiza una reformulación del denominado control de transparencia -la de 9 de mayo solo lo prevé para consumidores-, superando la concepción que hasta el momento se venía conociendo. Pasamos de una transparencia limitada al control de incorporación de las cláusulas, limitado a la claridad y comprensión gramatical de las mismas, a un control de transparencia que exige, además de esto, una comprensión real de las cargas jurídicas y económicas de tales cláusulas en el devenir del contrato ${ }^{25}$. Para ello el Supremo apela a los criterios recogidos en la LCGC, TRLGDCU y la Directiva 93/13/CEE.

Siguiendo con la reformulación jurisprudencial del control de transparencia, es transcendente, en este sentido, la STJUE 26 de febrero de 20I5. En esta ocasión el TJUE da respuesta a la cuestión planteada acerca del carácter abusivo de unas cláusulas con comisión de riesgo, las cuales permiten a la entidad bancaria alterar de forma unilateral el tipo de interés del préstamo. Declara, teniendo presente la Directiva 93/13/CEE, la atribución al tribunal nacional de la competencia para valorar si tales cláusulas son abusivas o no conforme al moderno control de transparencia. Para el tema que nos ocupa, es destacable lo explicado en el Fundamento 73 y 74, los cuales vienen a decir que la extensión del control va más allá de la claridad y comprensión gramatical, de modo que el consumidor deberá conocer la carga económica derivada del contrato y la posición jurídica que ostenta con la ejecución del mismo. Además, expone la idea relativa a la obligación del tribunal de valorar el asunto prestando atención a todos los elementos de hecho -incluyendo la

${ }^{22}$ Cordero Lobato, E., Ibídem, págs. 2-4.

${ }^{23}$ STS 9 mayo 20I3 (RJ 2013/3088) \210: «Lo que permite concluir que, además del filtro de incorporación, conforme a la Directiva 93/I3/CEE y a lo declarado por esta Sala en la Sentencia 406/20I2, de I8 de junio, el control de transparencia, como parámetro abstracto de validez de la cláusula predispuesta, esto es, fuera del ámbito de interpretación general del Código Civil del «error propio» o «error vicio», cuando se proyecta sobre los elementos esenciales del contrato tiene por objeto que el adherente conozca o pueda conocer con sencillez tanto la «carga económica» que realmente supone para él el contrato celebrado, esto es, la onerosidad o sacrificio patrimonial realizada a cambio de la prestación económica que se quiere obtener, como la carga jurídica del mismo, es decir, la definición clara de su posición jurídica tanto en los presupuestos o elementos típicos que configuran el contrato celebrado, como en la asignación o distribución de los riesgos de la ejecución o desarrollo del mismo».

${ }^{24}$ STS I8 junio 2012 (RJ 20I2/8857): esta establece la primera delimitación del control de transparencia separado del control de incorporación «control de inclusión, particularmente el referido al criterio de transparencia respecto de los elementos esenciales del contrato, tiene por objeto que el cliente conozca o pueda conocer (aquellas condiciones generales de la contratación que afectan a) la carga económica que en conjunto el contrato supone para él y, a su vez, la prestación económica que va a obtener de la otra parte».

${ }^{25}$ Plaza PenAdÉs, J., «Del moderno control de transparencia y de la doctrina del Tribunal Supremo sobre la 'irretroactividad' de las cláusulas suelo», Diario La Ley, $n^{\circ} 8547,2015$. 
información dada por el prestamista- y examinando el nivel de atención que cabe esperar del consumidor medio ${ }^{26}$.

\section{La declaración de nulidad de las cláusulas abusivas}

\section{III.I. Efectos de la declaración de nulidad}

Una vez sentada doctrina jurisprudencial sobre el doble control de transparencia al que deben ajustarse las cláusulas para no ser declaradas abusivas, toma especial relevancia en relación con esta cuestión el pronunciamiento de nuestro Alto Tribunal sobre los efectos de la declaración de nulidad de las cláusulas suelo.

De conformidad con los arts. 8 LCGC y 83 TRLGDCU, los cuales prevén la misma consecuencia jurídica dispuesta por el art. 6 de la Directiva 93/13/CEE, tanto el TS como los tribunales menores entienden que la sanción prevista para los contratos de préstamo hipotecario que incluyen cláusulas suelo no transparentes es la nulidad parcial. En este sentido, la doctrina explica que se trata de cláusulas nulas de pleno derecho por contravenir la normativa vigente ${ }^{27}$.

El TS admite en la sentencia de mayo de 2013 la regla general del art. 1303 del Código Civil $^{28}$ el cual establece que una vez declarada la nulidad, corresponderá la restitución recíproca de las cosas objeto del contrato, más los frutos e intereses. A esta regla la denomina el TS restitutio in integrum. A pesar de ello, opta por limitar dicha retroactividad, según señala, porque los efectos de las declaraciones de nulidad no pueden ser impermeables a los principios generales del Derecho. Por ello, me parece conveniente realizar un breve examen acerca del fenómeno de la nulidad contractual y sus efectos.

Pues bien, los efectos de la declaración de nulidad aparecen regulados, como he dicho, en el art. ${ }_{3} 303$ CC. Este precepto nos lleva a pensar a priori que la declaración judicial de nulidad de las cláusulas suelo no transparentes conllevaría la devolución de las cantidades cobradas por la aplicación de dichas cláusulas, dejando las prestaciones entre la entidad y el consumidor en un statu quo inmediatamente anterior a la perfección del contrato, es decir, como si nunca hubiesen existido las cláusulas nulas ${ }^{29}$. Ésta es la regla general de la restitución subsiguiente a la declaración de nulidad.

Pese a que la regla general que rige la declaración de nulidad de una cláusula, siguiendo el criterio quod nullum est nullum effectum producit, es la retroactividad de los efectos al momento de celebración del contrato - ex tunc-, declara el TS la limitación de los efectos retroactivos a la fecha de la STS 9 mayo $2013^{30}$. De esta forma, se aleja del contenido dispuesto por el $\mathrm{CC}$, fundamentando tal determinación en una serie de razones más económicas que jurídicas, que ulteriormente entraré a explicar.

\footnotetext{
${ }^{26}$ Plaza Penadés, J., loc. cit.

${ }^{27}$ Delgado EcheVerría, J. / Parra Lucán, M.A., Las nulidades de los contratos. En la teoría y en la práctica, Dykinson, Madrid, 2005. Pág. I92. Aquí se prevé que solo está prevista en interés del adherente o de su fiador.

${ }^{29}$ Lasarte Álvarez, C., Principios de Derecho Civil III: Contratos, Marcial Pons, Madrid, 20I3, pág. I33.

${ }^{30}$ STS 9 mayo 2013 (RJ 2013/3088) en el apartado décimo del Fallo, cuyo tenor literal dice «no hay lugar a la retroactividad de esta sentencia, que no afectará a las situaciones definitivamente decididas por resoluciones judiciales con fuerza de cosa juzgada ni los pagos ya efectuados en la fecha de publicación de esta sentencia».
} 
III.2. El problema de la retroactividad de la declaración de nulidad de las cláusulas suelo

Como ya he dicho, la primera sentencia de nuestro Alto Tribunal sobre esta cuestión declara la nulidad de las cláusulas suelo objeto de aquella controversia por falta de transparencia real. Sin embargo, no admite la retroactividad -intrínseca a la declaración de nulidad-apelando para ello a la seguridad jurídica y sobre todo al orden público económico. Tras este pronunciamiento se produjo una cascada de demandas contra las cláusulas suelo de multitud de contratos de préstamos hipotecarios ${ }^{31}$, las cuales afrontaban los tribunales con una enorme incertidumbre, sobre todo en lo relativo a la eficacia de la declaración de nulidad de estas cláusulas. De forma más concreta, las controversias versan acerca de la devolución íntegra de las cantidades indebidamente cobradas por aplicación de aquellas cláusulas suelo declaradas nulas por abusivas.

Las alegaciones del Supremo tienden a reforzar la validez de las cláusulas suelo en abstracto, pero no justifican la actuación de las entidades con relación a los deberes de transparencia exigidos. Esto, en opinión de CORDERO LOBATO parece indicar que la pretensión del TS de defender la no retroactividad se debe al hecho de que las cláusulas suelo no transparentes han sido empleadas durante muchos años por entidades ${ }^{32}$, empleando además en su fundamentación razones más económicas que jurídicas.

Apenas 2 años después, el TS sienta doctrina con la sentencia de 25 de marzo de 2015, en la que declara que procederá la devolución de las cantidades cobradas por aplicación de las cláusulas suelo solo desde 9 de mayo de 2013. Para ello apela a los mismos argumentos empleados en aquélla, hasta el punto realizar una remisión en bloque a ella, como así expresamente señala ${ }^{33}$. Las dudas surgidas a partir del primer pronunciamiento no han sido solventadas con la nueva sentencia, continuando así las críticas al fallo del Supremo. Este segundo pronunciamiento tiene un voto particular de Orduña Moreno y al que se adhiere O'Callaghan Muñoz.

A continuación, paso a realizar un estudio en torno a las controversias existentes acerca de los efectos de la mal llamada irretroactividad de la nulidad de las cláusulas suelo declarada por el Supremo.

\section{III.2.1. Sistema de fuentes y primacía de la ley}

\section{III.2.1.1. La jurisprudencia como fuente complementaria en nuestro ordenamiento jurídico}

En concordancia con el art. I.6 de nuestro Código Civil, y siguiendo lo expuesto por LASARTE ÁlVAREZ, debemos partir de la base de que existe en el sistema de fuentes una primacía de la ley y un papel secundario de los criterios que fijan los jueces y tribunales al interpretar las normas. En España, al contrario de lo que ocurre en los países anglosajones, la jurisprudencia no constituye creación libre del Derecho, sino que actúa como fuente

\footnotetext{
${ }^{31}$ vid. lo expuesto en la nota 4 de este trabajo sobre la incidencia estadística de las cláusulas suelo en los préstamos hipotecarios en España.

${ }^{32}$ Cordero Lobato, E., loc. cit., pág. I32.

${ }^{33}$ STS 25 marzo 2015 (RJ 2015/735) F.D. $8^{\circ}$ : «entendemos necesario ofrecer respuesta a tan debatida cuestión, no revisando la fijada sino despejando dudas y clarificando su sentido».
} 
complementaria, y, conforme al art. I.7 del Código Civil, ésta debe encontrar sustento legal en el sistema de fuentes de nuestro ordenamiento ${ }^{34}$.

Hallamos tribunales de instancia cuya fundamentación parar declarar la irretroactividad se basa principalmente en los mismos argumentos alegados por el Supremo, porque entienden que como tribunales menores les es vinculante lo establecido por el Alto Tribunal, sin tener potestad para corregir la decisión. Ésta ha sido la opinión a la que se sujeta la SJM de Murcia, de I2 de noviembre de 20I3, la cual se limita a apelar a razones de seguridad jurídica y de congruencia con la doctrina del TS. La SAP Córdoba 3I octubre 2013 razona lo siguiente «no cabe acoger la doctrina del TS en lo que nos gusta, la abusividad, y rechazarla en lo que no nos gusta, la retracción de los efectos de la nulidad» y como tribunal de instancia debe acogerse a la doctrina del Supremo. La SAP Zaragoza 8 enero 20I4 reconoce la fuerza informadora atribuida al TS el art. I.6 CC, y conforme a la exigencia de seguridad jurídica de la CE, opta la AP por declarar la no restitución de cantidades. En la misma línea se dicta también la SAP Badajoz I4 enero 2014.

En contraposición a este criterio jurisprudencia, encontramos la opinión de autores que, tras interpretar el I.6 CC, consideran que debe primar la ley sobre la jurisprudencia, cuya función es solo complementar el ordenamiento jurídico.

\section{III.2.1.2. El imperio de la ley sobre los principios generales del Derecho}

Los tribunales no pueden corregir las normas aplicables cuando su interpretación sea clara ni acudir a otras que regulen supuestos distintos cuando no exista una laguna legal que integrar.

El art. I.7 CC establece el deber inexcusable para los jueces de resolver las cuestiones que se les planteen conforme al sistema de fuentes fijado. Dicho deber es obviado por el TS al no aplicar el art. I303 CC, el cual, además de ser imperativo, no da lugar a interpretaciones. Además, el art. II7 CE establece el deber de sometimiento de los jueces únicamente al imperio de la ley a la hora de administrar justicia.

De esta forma, los tribunales están sometidos primeramente a la ley como fuente del Derecho, por lo que en este caso prima lo dispuesto en el art. I303 CC, cuyas excepciones deben aplicarse restrictivamente, ya que de lo contrario se está modificando por la jurisprudencia una norma legal imperativa, hecho permitido en nuestro ordenamiento jurídico.

Es verdad que el TS se apoya en preceptos legales para limitar la retroactividad. Pero dichos preceptos están previstos para supuestos de hecho distintos al caso que nos ocupa, por lo que no sirven de base para excepcionar la aplicación de la restitución íntegra de cantidades.

En palabras de PERTÍÑEZ VÍlCHEZ, el argumento esgrimido por el Supremo es el riesgo de graves trastornos en el orden público económico. De esta forma nuestro Alto Tribunal antepone un principio general del Derecho a un precepto imperativo, por lo que en esta ocasión el orden público no puede ser fuente de Derecho ni criterio para interpretar

${ }^{34}$ Lasarte Álvarez, C., Principios de Derecho Civil I: Parte general y Derecho de la persona, Marcial Pons, Madrid, 20II, págs.48-49. 
normas jurídicas. Además, este hecho impide que el Supremo pueda sentar jurisprudencia en lo relativo a esta cuestión ${ }^{35}$.

Lo mismo ocurre con el fundamento referido a la seguridad jurídica como principio general del Derecho empleado por el TS para alejarse del contenido imperativo inserto en un precepto del Código Civil.

Pues bien, atendiendo al imperio de la ley fijado en nuestro sistema de fuentes, la solución debía haber sido la derivada de la literalidad del art. I303 CC, el cual establece la restitución de las prestaciones una vez se declare la nulidad de la obligación, optando así por condenar a las entidades a la devolución íntegra de cantidades. A la literalidad de este precepto se ajustan la SJPI Orense I3 mayo 20I3, SAP Álava 9 julio 20I3, SAP Málaga I2 marzo 20I4, optando éstas por declarar la regla general de la retroactividad con efectos ex tunc.

\section{III.2.2. Diferenciación entre acciones individuales y colectivas}

Recordemos, STS 9 mayo 2013 da respuesta a una acción colectiva de cesación interpuesta por una asociación de consumidores, mientras que la acción ejercitada en la demanda que da lugar al pronunciamiento de marzo de 2015 es una acción individual de nulidad.

Las diferencias existentes entre una acción colectiva de cesación y una acción individual de impugnación son trascendentes en lo relativo a dos aspectos. Por un lado, es importante tener en cuenta la distinción a la hora de examinar la inexistencia de cosa juzgada, y por otro lado, cobra importancia a la hora de valorar el riesgo en el orden público económico.

\section{III.2.2.1. Respecto de la inexistencia de cosa juzgada}

En primer lugar, la acción de cesación tiene por objeto el cese de la conducta -dejar de utilizar determinada cláusula- y la prohibición de reiteración futura. Estas dos pretensiones, aunque diferentes, no son autónomas, pues el legislador optó por configurarlas de forma conjunta ${ }^{36}$.

Dicha acción no incluye en su petitum la restitución de las cantidades cobradas de más por la aplicación de dichas cláusulas, de modo que la vía adecuada para solicitar la devolución de las cantidades íntegras es la acción de restitución -con posible acumulación a la acción de cesación-.

Pues bien, si se ejercita una acción colectiva de cesación y la sentencia es estimatoria, se condena al demandado a eliminar y a abstenerse de utilizar en lo sucesivo dicha cláusula ${ }^{37}$. Pero además prevé el art. I2.2 LCGC, y en mi opinión esto muestra la diferencia entre ambas, la acumulación a ésta de una acción de devolución de las cantidades

${ }^{35}$ Pertíñez Vílchez, F., «La restitución de las cantidades indebidamente cobradas en virtud de cláusulas suelo en contratos de préstamo hipotecario tras la STS 9 de mayo de 20I3», en Diario La Ley, $n^{\circ}$ 8154 .

${ }^{36}$ Ariza Colmenarejo, M.J., La acción de cesación como medio para la protección de de los consumidores $y$ usuarios, Aranzadi, Cizur Menor, 20I2, pág. I4I-I42.

${ }^{37}$ Delgado Echeverría, J. / Parra LucÁn, M.A., op. cit., pág. Ig6. 
cobradas de más por la utilización de las cláusulas abusivas. Dicha reclamación patrimonial debe ejercitarse directamente por los perjudicados, mientras que la acción de cesación puede ejercitarla un amplio número de legitimados, pero no los particulares perjudicados por la utilización de la cláusula.

En este sentido, LASARTE ÁLVAREZ examina la diferenciación entre ambos tipos de acciones a la que hace mención la LCGC en su Exp. Motivos y en su articulado. Concretamente, respecto de las acciones individuales, se expresa en ella: «el capítulo II sanciona con nulidad las cláusulas generales no ajustadas a la ley, determina la ineficacia por no incorporación de las cláusulas que no reúnan los requisitos exigidos en el capítulo anterior para que puedan entenderse incorporadas al contrato. Esta nulidad, al igual que la contravención de cualquier otra norma imperativa o prohibitiva, podrá ser invocada, en su caso, por los contratantes conforme a las reglas generales de la nulidad contractual, sin que puedan confundirse tales acciones individuales con las acciones colectivas de cesación o retractación reconocidas con carácter general a las entidades o corporaciones legitimadas para ello en el capítulo IV y que tienen un breve plazo de prescripción» ${ }^{38}$.

Por otro lado, respecto de las acciones colectivas expresa el punto IV de la Exp. Motivos lo siguiente: «el capítulo IV regula las acciones colectivas encaminadas a impedir la utilización de condiciones generales que sean contrarias a la ley, como son la acción de cesación, dirigida a impedir la utilización de tales condiciones generales; la de retractación, dirigida a prohibir y retractarse de su recomendación, siempre que en algún momento hayan sido efectivamente utilizadas, y que permitirá actuar no sólo frente al predisponente que utilice condiciones generales nulas, sino también frente a las organizaciones que las recomienden, y la declarativa, dirigida a reconocer su cualidad de condición general e instar la inscripción de las mismas en el Registro de Condiciones Generales de la Contratación. Todo ello sin perjuicio de la posibilidad de ejercitar las acciones individuales de nulidad conforme a las reglas comunes de la nulidad contractual o la de no incorporación de determinadas cláusulas generales» ${ }^{39}$.

Sobre la distinción del régimen jurídico de las diferentes acciones previstas en la LCGC, se puede encontrar la SAP Álava 9 julio 20I3. En este pronunciamiento se señalan, por un lado, los rasgos de la acción de cesación. Ésta presenta una legitimación activa restringida y se explica que, dada su finalidad principal consistente en el cese de la eficacia de la relación jurídica, los efectos de ésta serán solo a futuro. Por otro lado, indica que la acción individual de nulidad la puede ejercitar cualquier afectado y la eficacia es ex tunc ${ }^{40}$.

Sobre este aspecto, cabe decir también, que el objeto de la acción colectiva de cesación no es una cláusula contenida en un contrato concreto ya perfeccionado, sino una

\footnotetext{
${ }^{38}$ LaSARTe Álvarez, C., Manual sobre protección de consumidores y usuarios, Dykinson, Madrid, 20I3, págs. 280-28I.

${ }^{39}$ LASARTE Álvarez, C., Ibídem, pág. 28I.

${ }^{40}$ SAP Álava 9 julio 2013 (AC 20I3\I538): «Acción de cesación, presenta una legitimación activa restringida (art. I6 LCGC), con carácter general es imprescriptible (art. I9 LCGC) y sus efectos sólo son hacia el futuro, pues su finalidad es que cese la eficacia jurídica de una relación contractual, ya que según el art. I2 LCGC la cesación pretende la condena a que deje de surtir efecto «en lo sucesivo»; sin embargo, la acción individual de nulidad la puede ejercitar cualquier afectado y su eficacia es ex tunc según los arts. 8 y 9 LCGC».
} 
condición general utilizada por un predisponente para un determinado tipo de contrato en abstracto, es decir, al margen de su incorporación a un concreto contrato ${ }^{4 \mathrm{I}}$.

Las diferencias entre ambas acciones quedan patentes, por lo que vamos a ver ahora la trascendencia que tiene dicha distinción en el caso que aquí nos ocupa.

Señala el Supremo en la sentencia de 9 mayo de 2013 que los particulares que lo estimen conveniente deberán interponer acción individual solicitando la devolución de cantidades, cuya procedencia se examinará atendiendo a cada caso concreto.

A las diferencias entre la acción colectiva y la acción individual de ambas sentencias hace referencia el Supremo en su pronunciamiento de 25 de marzo de 2015, para acabar concluyendo en su declaración que el efecto jurídico de una y otra es el mismo ${ }^{42}$.

En cuanto a la naturaleza de ambas acciones, entiende que no resulta trascendente, para el caso que nos ocupa, el hecho de tratarse de una acción individual o colectiva, «puesto que el conflicto jurídico es el mismo al estar en presencia de una doctrina sentada por la sentencia del Pleno de 9 de mayo de 2013 para todos aquellos supuestos en que resulte, tras su examen, el carácter abusivo de una cláusula suelo inserta en un préstamo de interés variable cuando se den las circunstancias concretas y singulares que el Tribunal Supremo entendió que la tiñen de abusiva» ${ }^{43}$.

Y en lo relativo al hecho de no haberse acumulado devolución de cantidades en la STS 9 mayo 2013, la STS 25 marzo 2015 se limita a exponer lo declarado por aquella sentencia: «la finalidad de las acciones de cesación no impide el examen de los efectos de la nulidad determinante de la condena a cesar en la utilización de las cláusulas abusivas y a eliminar de sus contratos los existentes, cuando éstas se han utilizado en el pasado» ${ }^{44}$.

De esta forma, en mi opinión y a la luz de la opinión de la doctrina, la sentencia comete un error considerando que la controversia jurídica es la misma ejercitando una acción colectiva de cesación y una acción individual a la que se acumula acción de restitución de cantidades.

En el marco de la STS 9 mayo 2013, el Ministerio Fiscal consideró oportuno solicitar pronunciamiento del tribunal acerca del factor tiempo en los efectos de la declaración de nulidad de las cláusulas abusivas. ORDUÑa MORENO considera que la intervención del MF se debió a «razones económicas del enjuiciamiento abstracto propio de la acción de cesación ${ }^{45}$, por lo que el pronunciamiento al respecto no puede entenderse referido a la generalidad de las cláusulas suelo.

${ }^{41}$ GarCía VicEnTE, J.R., «La contratación con consumidores», Tratado de contratos II: contratación con consumidores, contratos de adhesión y contratación electrónica, contratos con finalidad traslativa de dominio, contratos de cesión temporal de uso $y$ disfrute, Tirant Lo Blanch, Valencia, 2009, pág.I67I.

${ }^{42}$ STS 25 marzo 2015 (RJ 2015/735) F.D. $7^{\circ}$ : «no resulta trascendente, al efecto aquí debatido, que se trate de una acción colectiva o de una individual, puesto que el conflicto jurídico es el mismo y estamos en presencia de una doctrina sentada por la repetida sentencia para todos aquellos supuestos en que resulte, tras su examen, el carácter abusivo de una cláusula suelo inserta en un préstamo de interés variable cuando se den las circunstancias concretas y singulares que el Tribunal Supremo entendió que la tiñen de abusiva, debiendo ser, por ende, expulsada del contrato».

${ }^{43}$ ACHÓN BRUÑén, M.J., «La retroactividad parcial de la declaración de nulidad de la cláusula suelo: los discutibles argumentos de la STS de 25 de marzo de 2015», Diario Ley $n^{\circ} 8561,2015$.

${ }^{44}$ STS 9 mayo 2013 (RJ 2013/3088) \282.

${ }^{45}$ Voto particular de Orduña Moreno al fallo de la STS 25 marzo 2015. 
Por lo tanto, no existe identidad de naturaleza y función entre las acciones enjuiciadas en STS 9 mayo 2013 y la STS 25 marzo 20I5, lo que conlleva ausencia de efectos de cosa juzgada material de la primera sobre la segunda. De este modo, no queda justificado que, en la segunda, el TS realice una remisión en bloque a la primera, quedando así la sentencia de marzo de 2015 carente de fundamentación técnica de manera jurídicamente injustificada.

Y así, la STS de mayo de 2013 no extiende sus efectos a aquellas partes que no intervinieron en el procedimiento, por lo que no serán admisibles las excepciones procesales referidas a cosa juzgada y litispendencia.

Además, cabe recordar que en dicho procedimiento no se solicitó eficacia de la sentencia ultra partes, y la acción interpuesta fue de cesación, sin acumular a ella acción de restitución. Por ello, como declara la SJPI Gijón 30 septiembre 2013 «si el pronunciamiento peca de incongruente, únicamente puede tomarse como una declaración obiter dicta».

Y en cuanto a la inexistencia de cosa juzgada, en relación con la posibilidad de no

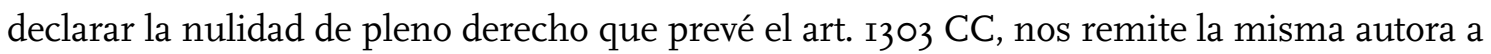
lo expuesto por una sentencia que admite la vinculación de los criterios referidos a la consideración de abusivas de las cláusulas fijados por el pronunciamiento de mayo de 2013, pero entiende que éste no le obliga a aplicar lo relativo a los efectos de la declaración de nulidad $^{46}$.

A esta opinión se suman autores como PERTíÑEZ VílCHEZ, que entiende que la sentencia no puede tener efectos de cosa juzgada material en lo relativo a la extensión del efecto no devolutivo de las cantidades a aquellos consumidores que no intervinieron en el procedimiento ${ }^{47}$, de conformidad con el art. 222.3 LEC.

Y este autor tacha de incongruente el pronunciamiento del TS acerca de la restitución -no restitución mejor dicho- de cantidades, debido a la naturaleza y función de la acción ejercitada en la primera sentencia -acción de cesación- y a la que no se acumuló acción de tutela de los intereses de los consumidores, prevista en el art. II LEC. Por lo que, al no haber acción accesoria, y teniendo presente la limitación de la legitimación del Ministerio Fiscal a interponer demanda de cesación, cree que el tribunal desprecia los límites del principio de congruencia procesal. De esta forma deduce que lo referido en la sentencia a los efectos no retroactivos deberá considerarse como un obiter dicta ${ }^{4}$, aspecto al que ya me he referido anteriormente.

\section{III.2.2.2. Respecto del orden público económico}

El argumento de peso esgrimido para limitar los efectos retroactivos de la declaración de nulidad de las cláusulas suelo es el riesgo de graves trastornos en el orden

${ }^{46}$ ACHÓn BRUÑÉn, M.J., «Once argumentos de peso en contra de la irretroactividad de la declaración de nulidad de la cláusula suelo» Diario La Ley n 8366, 20I4 remite a SJM n ${ }^{\circ} 5$ de Barcelona de I7 de junio de 20I3 que declara que «si bien los criterios del Alto Tribunal los considera vinculantes en su integridad para declarar la abusividad de la cláusula suelo, no se siente obligado a aplicar el criterio relativo a los efectos consecuentes de dicha nulidad».

\footnotetext{
${ }^{47}$ Pertíñez Vílchez, F., «Restitución...» loc. cit.

${ }^{48}$ Pertíñez Vílchez, F., Ibídem.
} 
público económico que conllevaría la devolución íntegra de las cantidades cobradas. Este aspecto ha sido muy criticado por la doctrina y la jurisprudencia.

En opinión de ACHÓN BRUÑé $N^{49}$, no es admisible la alegación del TS al trastorno grave del orden público económico como argumento para la no retroactividad en aquellos supuestos en que la acción interpuesta sea una acción individual.

A este respecto, la SJM Bilbao 2I octubre $2013^{5 \circ}$ viene a decir, en relación con lo anterior, que la inclusión de la cláusula suelo en el contrato en ningún caso debe servir para argumentar el perjuicio al consumidor. Critica el argumento ofrecido por el TS apoyándose en un principio de Derecho -nemo auditur propiam turpitudinem allegans- el cual quiere decir que nadie puede beneficiarse de su propia torpeza. Y, reprocha además, que el juez emplee como argumento el orden económico de las entidades bancarias ignorando los perjuicios económicos sufridos por los consumidores que no ven restituidas las cantidades que pagaron de más por aplicación de unas cláusulas declaradas nulas.

Encontramos sentencias de tribunales inferiores a favor de declarar la irretroactividad de la nulidad por considerar que no es trascendente la diferenciación entre acción colectiva e individual a la hora de valorar los efectos de la nulidad. La SAP Granada I8 octubre 20I3, SAP Zaragoza 8 enero 20I4, SAP Cáceres 24 febrero 20I4, entre otras, apelan a los mismos argumentos esgrimidos por el Supremo para desestimar la devolución de cantidades.

En contraposición, hallamos otros pronunciamientos como SJM Bilbao I julio 2013, SAP Álava 9 julio 20I3, SAP Málaga I2 marzo 20I4, cuyos magistrados optan por declarar la retroactividad de la nulidad. De este modo, condenan a la entidad a la devolución íntegra de cantidades por considerar que, tratándose de acciones individuales de impugnación, el riesgo de trastornos en el orden público económico no se ve vulnerado.

Aclara el Alto Tribunal en el pronunciamiento de marzo de 2015 que el trastorno al orden socio económico no se debe a la devolución de las cantidades de un procedimiento concreto, sino a la acumulación de las cantidades de todos los pronunciamientos al respecto, como así declara en su fundamento de Derecho noveno ${ }^{5 \mathrm{I}}$.

En este sentido, acertadamente critica el magistrado del voto particular que el riesgo de trastornos económicos venía atendiendo a las circunstancias concretas del el marco económico en el cual se desenvolvió dicha sentencia. Y dicho riesgo, si tenemos presentes las circunstancias económicas actuales, ha quedado atenuado, de manera que este argumento pierde sentido en el momento en que se dictó la STS 25 marzo 2015.

\footnotetext{
${ }^{49}$ ACHÓn BRUÑ̂́n M.J., «Once...» loc. cit.

${ }^{50}$ SJM Bilbao 2I octubre 20I3 (AC 20I3/2269): «ningún perjuicio económico material se le puede causar por el juego de la cláusula (pérdida de un beneficio superior no significa ingresos inferiores a los gastos), más allá de equilibrar el beneficio obtenido por el devenir de los tipos».

${ }^{51}$ STS 25 marzo 2015 (RJ 20I5/735) F.D. 9 : «La afectación al orden público económico no nace de la suma a devolver en un singular procedimiento, que puede resultar ridícula en términos macroeconómicos, sino por la suma de los muchos miles de procedimientos tramitados y en tramitación con análogo objeto».
} 


\section{III.2.3. La figura de la ineficacia contractual}

III.2.3.1. Ineficacia contractual derivada de actos y negocios jurídicos

Debido a la complejidad jurídica y técnica de la figura de la ineficacia contractual de los actos y negocios jurídicos se hace necesario sentar unas directrices de interpretación sobre esta figura jurídica.

En este caso concreto nos encontramos ante un supuesto de invalidez, la cual, siguiendo lo expuesto por LACRUZ BERDEJO, podemos definir como «la negación de la fuerza jurídica vinculante de un contrato por defectos en sus elementos constitutivos o ilicitud de su contenido, en los casos previstos por la ley» $»^{52}$. Esta afirmación es importante a la hora de matizar la distinción entre ineficacia e invalidez, de modo que «todo contrato inválido es ineficaz, o presenta anomalías en su eficacia, pero la proposición inversa no es cierta. No hay contratos inválidos plenamente eficaces, pero sí hay contratos ineficaces plenamente válidos» ${ }^{53}$. Es decir, todo lo inválido es ineficaz, pero no todo lo ineficaz es inválido.

Esta cuestión ha sido examinada por el Supremo en sentencias como la de 28 de octubre de 2014 y Io de diciembre de 20I4, cuyas pautas seguidas podrían sintetizarse en la siguiente idea: a la hora de delimitar la aplicación de la ineficacia contractual, habrá que examinar el caso concreto en cuestión, atendiendo a las determinadas circunstancias del fenómeno que da origen al régimen de la ineficacia.

Pues bien, la jurisprudencia nacional y comunitaria consagrada a este respecto no ha sido tenido en cuenta a la hora de dictar la STS 25 marzo 20I5, como queda demostrado en el hecho de realizar ésta una remisión en bloque a la STS de mayo de 2013, sin entrar a fundamentar sobre criterios relativos a la ineficacia contractual de las cláusulas abusivas en el ejercicio de una acción individual de nulidad, cuya complejidad hace necesaria una valoración exhaustiva y directa al respecto. Es decir, el Supremo debía haber tenido presente la complejidad jurídica de la figura de la ineficacia contractual, la cual exige ser valorada de forma íntegra y en profundidad, mediante un análisis directo de cada caso concreto.

\section{III.2.3.2. Ineficacia contractual en relación con la diferenciación entre retroactividad de la nulidad $y$ retroactividad de la sentencia}

La crítica al Supremo en lo relativo a la ineficacia contractual no queda ahí. Como he dicho, la complejidad jurídica de este fenómeno queda patente, pero ello no justifica el error cometido por el TS acerca de la diferenciación entre ineficacia de una cláusula abusiva y la ineficacia en relación con el fenómeno de la retroactividad.

La STS 25 marzo 2015 establece, en su fundamento de Derecho noveno: «La Sentencia del Pleno de 9 mayo 20I3, al plantearse a instancias del Ministerio Fiscal el elemento temporal de la sentencia, analizó los efectos retroactivos de la nulidad para, a continuación, razonar la posibilidad de limitar la y concluir, en su sistematizado discurso, por declarar la irretroactividad de la sentencia en los términos que éste especifican».

${ }^{52}$ LACRUZ Berdejo, J.L., Elementos de Derecho Civil II: Derecho de obligaciones. Parte general Teoría general del contrato, Dykinson, Madrid, 20II, pág. 53I.

${ }^{53}$ LACRUZ BERDEJO, J.L., Ibídem. 
ORDUÑA MORENO discute lo anterior, al considerar que se incurrió en un error conceptual en la delimitación de la aplicación de la ineficacia de una cláusula considerada abusiva en relación con la retroactividad ${ }^{54}$. Así, entiende que la asimilación equivocada de los efectos retroactivos de la nulidad contractual con los de la sentencia dictada provocó que el pronunciamiento se fundamentara en la retroactividad respecto de los pagos ya efectuados en la fecha de su publicación, con relación a consumidores que no formaron parte del proceso, sin apoyare para ello en ningún sustento normativo.

Este magistrado opina que lo correcto hubiera sido matizar que el efecto temporal del pronunciamiento del tribunal no tiene efectos retroactivos, sin que ello impida desestimar la devolución de las cantidades cobradas de más por aplicación de cláusulas suelo declaradas nulas, basando esta idea en la naturaleza de la acción de cesación en la ausencia de acciones individuales o accesorias que solicitaran el efecto devolutivo de los pagos.

En esta línea se encuentra el pensamiento de PeRTíñEZ VílCHEZ, quien deduce que la sentencia de 9 de mayo declara su propia irretroactividad, y no la irretroactividad de la nulidad de la cláusula suelo, por lo declarado expresamente en ella y por la propia naturaleza de la acción ejercitada ${ }^{55}$.

Este fundamento es empleado en la SAP Jaén 27 marzo 20I4, la cual declara la retroactividad de la nulidad de la cláusula suelo, al entender que con ello no contradice lo expuesto por la STS 9 mayo 2013, porque considera que ésta no declara la irretroactividad como regla general, sino la irretroactividad de la propia sentencia. Esta misma línea sigue la SJM Bilbao I9 junio 20I3 al determinar que la irretroactividad a la que hace referencia el TS se dirige a solo a su sentencia, y no a la nulidad de la cláusula suelo en general.

\section{III.2.3.3. Ineficacia derivada de acciones de impugnación en relación con el efecto restitutorio $y$ alcance ex tunc}

Aclarado el hecho de que el fundamento normativo de la retroactividad no puede servir de base para delimitar el alcance de la ineficacia de la cláusula suelo, y sentadas las diferencias entre la acción de cesación y la acción individual, considera ORDUÑA MORENO que la cuestión no se abordó adecuadamente. Deduce que el asunto requería un examen valorativo, dinámico y flexible, ya que si atendemos a una valoración meramente dogmática la ley declara la nulidad de pleno derecho, en virtud de los arts. 8. I LCGC y I303 CC. Esta idea es la que se debe entender atendiendo a la causalidad jurídica, de tal modo que, los fundamentos referidos a la devolución de cantidades atienden a las claves valorativas de la ineficacia, ya abordadas por la jurisprudencia nacional y comunitaria. Dicho de otro modo, la ineficacia, en este caso, no encuentra sustento en la retroactividad normativa, de tal manera que la devolución de cantidades deberá determinarse valorando los criterios de eficacia y control de las condiciones generales de la contratación, que son los que dan lugar a la nulidad de dichas cláusulas.

Señala además, que tratándose de una contratación sometida a la normativa sobre condiciones generales de la contratación, la ineficacia que aquí interesa es -cito literalmente

\footnotetext{
${ }^{54}$ vid. lo expuesto en la nota 30 de este trabajo sobre la no retroactividad declarada por la STS 9 mayo 2013.

${ }^{55}$ Pertíñez Vílchez, F., loc. cit.
} 
del voto-: «funcional», «relativa», «parcial» e «insanable». En este sentido, es destacable que el control de abusividad se debe examinar atendiendo al momento de celebración del contrato, por ser el momento donde las entidades tenían que haber cumplido los deberes exigidos por el doble filtro de transparencia.

La acción individual de impugnación ejercitada da lugar a un pronunciamiento judicial cuyo alcance queda delimitado por dos aspectos. Por un lado, al tratarse de una ineficacia derivada de la nulidad de la cláusula abusiva, el efecto sistemático es, conforme al Código Civil la restitución de cantidades. Y por otro lado, en cuanto a los efectos temporales de dicha restitución, estos deben retrotraerse al momento de celebración del contrato - ex tunc-. Y es más, al no haber terceras partes que merezcan protección, ni otras circunstancias que merezcan tratamiento diferenciado a la hora de declarar la restitución, será ésta -la nulidad de pleno derecho con restitución de cantidades- la consecuencia directa de la ineficacia de la cláusula suelo declarada abusiva ${ }^{56}$.

\section{III.2.4. Prohibición de moderar la nulidad de las cláusulas abusivas}

\section{III.2.4.1. Respecto de la vulneración del «principio de no vinculación»}

El TS al declarar la -mal llamada- irretroactividad de la nulidad, no admitiendo la devolución íntegra de todos los consumidores, está vulnerando la normativa nacional y comunitaria en lo relativo a la prohibición de integrar en el contrato, aunque solo sea por un tiempo, la eficacia de una cláusula considerada abusiva.

A nivel comunitario, esta prohibición está recogida en el art. 6 de la Directiva93/13/CEE, y en el Informe de 27 de abril de 2000, de la Comisión sobre aplicación de dicha Directiva ${ }^{57}$. Dicha disposición ha sido interpretado por el TJUE como un precepto imperativo, y éste ha venido sentando en relación con él, el principio de no vinculación de una cláusula declarada a abusiva a los consumidores ${ }^{58}$.

En el ámbito interno, nuestro ordenamiento prevé dicha prohibición en el art. 83 TRLGDCU reformado por la Ley 3/20I4, para hacerlo compatible con el art. 6 de la Directiva.

En este sentido, encontramos la opinión del voto particular de la SAP Alicante I2 julio 20I3, cuyo magistrado considera más acertada la retroactividad de la nulidad de la cláusula suelo apelando a este principio jurisprudencial de no vinculación sentado por el TJUE. Así, entiende que el juez no puede modular la regla general de la retroactividad por un dato aleatorio como es la fecha de publicación de la STS 9 mayo 20I3. Y de este modo, deduce que los efectos no deben ser solo a futuro, sino también a pasado, ya que de lo contrario se pondría en peligro la protección integral de los consumidores.

\footnotetext{
${ }^{56}$ Voto particular de Orduña Moreno al fallo de la STS 25 marzo 2015.

${ }^{57}$ Informe de la Comisión sobre la aplicación de la Directiva 93/13/CEE del Consejo, de 5 de abril de I993, sobre las cláusulas abusivas en los contratos celebrados con consumidores, Bruselas, 27 de abril de 2000, COM (2000) 248 final, http://curia.europea.eu, 1 junio 2015.

${ }^{58} \mathrm{~A}$ este principio hacen referencia SSTJUE 26 abril 2012 (C-472/2010) y 30 mayo 2013 (C-397/20II) que vienen a decir que cuando se declare abusiva una cláusula contractual los órganos jurisdiccionales nacionales estarán obligados a aplicar todas las consecuencias que según el derecho nacional se deriven de ello para que el consumidor no resulte afectado por dicha cláusula.
} 
Viene al caso hacer mención aquí a la reciente SJM Zaragoza 27 abril $2015^{59}$ en la que el juez obliga la entidad a devolver todo lo cobrado por la utilización de la cláusula suelo apelando a la primacía del Derecho comunitario sobre el nacional. Como vemos, este pronunciamiento se dicta en fecha posterior a conocerse la segunda sentencia del Supremo negando el efecto restitutorio íntegro, lo que pone de manifiesto que las controversias derivadas de lo dictado por nuestro Alto Tribunal no han sido solventadas.

\section{III.2.4.2. Respecto de la buena fe como principio configurador de los deberes del predisponente}

Sobre la prohibición de modular la retroactividad de la nulidad admite el TJUE, en sentencia de 3 de junio de 2010, una excepción para aquellos supuestos en que se dé la buena fe de los interesados y, cumulativamente, el riesgo de graves trastornos para el orden público.

A este respecto, en lo que en nuestro caso interesa, la buena fe no debe tenerse en cuenta a favor del predisponente que impone la cláusula suelo en interés propio y sin cumplir los deberes de información exigidos, en perjuicio de los prestatarios de la hipoteca $^{60}$. Además, si se alega el principio de la buena fe, éste debería ser valorado atendiendo a las circunstancias de cada caso concreto, ya que de no hacerse así se contradice con lo previsto por el Derecho nacional -art. 83 TRLGDCU- y comunitario -art. 6 de la Directiva 93/13/CEE-.

En este sentido, es preciso añadir que la seguridad jurídica como principio moderador de la retroactividad solo podrá alegarse cuando todas las partes que intervienen en el litigio hubieran actuado de buena fe, hecho éste que no concurre en el caso que nos ocupa, debido al incumplimiento por parte de las entidades en sus deberes como predisponente. De esta manera, la pretensión del Supremo de crear seguridad jurídica ha provocado lo contrario, de modo que «se castiga a la parte perjudicada que ha obrado con buena fe y se beneficia a quien ha empleado cláusulas suelo de manera poco transparente» ${ }^{6 \mathrm{I}}$.

En postura contrapuesta, hallamos la SAP Burgos 28 enero 20I4, la cual, a este respecto, entiende que la cuestión está resuelta por el TS. Esta AP no concede la restitución de cantidades, alegando la facultad reconocida al juez para moderar la retroactividad, atendiendo a los criterios de buena fe, uso y ley, extendida ésta al orden público económico.

Una de las pocas novedades, si no la única, que introduce la STS de marzo de 2015 es la idea de que desde la publicación de la primera sentencia sobre cláusulas suelo, el predisponente no puede alegar buena $\mathrm{fe}^{62}$, porque ya sabe qué es lo que tiene que hacer, quedando sus deberes detallados en dicha sentencia.

${ }^{59}$ SJM Zaragoza 27 abril 20I5 (JUR 20I5\II9677): «no sólo estamos actuando como juez nacional, sino principalmente como juez comunitario, garante del derecho de la Unión y por tanto sometidos al derecho de la UE que tiene primacía» y «si el derecho aplicable nacional tiene un vínculo de conexión relevante, como es el caso, con el derecho de la UE debe aplicarse conforme a la normativa europea y la interpretación de la misma realizada por el TJUE, y no conforme a la normativa interna o la interpretación de la misma realizada por nuestros órganos jurisdiccionales, a mayor abundamiento, la jurisprudencia no es fuente del derecho».

${ }^{60}$ ACHÓn BRUÑ̂́n, M.J., «Once...», loc. cit.

${ }^{6}$ ACHÓN BRUÑ̃́n, M.J., Ibídem.

${ }^{62}$ STS 25 marzo 2015 (RJ 20I5/735) F.D. IO : «a partir de la fecha de publicación de la sentencia del pleno del 9 de mayo de 2013 no es posible ya la alegación de buena fe por los círculos interesados, pues esta sentencia 
Es verdad que tras la sentencia de 9 de mayo de 2013 los criterios de la falta de transparencia quedan expuestos para una generalidad de supuestos, por lo que las entidades ya saben cuáles son los criterios a los que se deben ajustar en su calidad de predisponente. De esta manera, la falta de información que lleva a la declaración de nulidad en ningún caso podrá verse respaldada por el principio de buena fe del prestamista en relación con el desconocimiento de la cuestión.

En lo que aquí interesa, compartiendo la opinión de ORDUÑA MORENO, no se puede admitir que el principio de buena fe al que se hace referencia pueda emplearse en perjuicio del consumidor, como ocurre en este caso al negar el efecto restitutorio de las prestaciones desde el momento de celebración del contrato.

\section{III.2.4.3. Respecto del efecto disuasorio de la ineficacia de las cláusulas abusivas}

Con el hecho de negar la retroactividad y no condenar a las entidades a la restitución de cantidades con efectos ex tunc, se da pie a que éstas incumplan los deberes de transparencia exigidos. Cuando se planteen las entidades si emplear o no otras posibles cláusulas controvertidas, optarán por aplicarlas sí o sí, ya que durante el tiempo de vida de dichas cláusulas, mientras no se ejerciten acciones de cesación contra ellas, se aprovecharán de los beneficios que les reputará la eficacia parcial de la cláusula, aunque en un momento futuro vaya a declararse abusiva. A este respecto se pronuncian las SSTJUE de I4 de junio de 2012 y de 2I de febrero de 20I3, las cuales declaran que si se permite al juez modificar el contenido de las cláusulas abusivas se contribuye a eliminar el efecto disuasorio que pretende la no aplicación de dichas cláusulas en los contratos con consumidores. Mención expresa se hace a ello en el voto particular de la STS 25 marzo 20I5, al exponer que «al efecto sancionador y disuasorio que informó la sentencia citada del TJUE, pues dada esta integración parcial de la eficacia de la cláusula nula, el mensaje que se transmite no es otro que el de la posibilidad de incumplir los especiales deberes de transparencia por el predisponente, sin sanción inicial alguna, que es lo que aquí ocurre al no estimarse la restitución de dichas cantidades con carácter ex tunc, esto es, desde el momento en que venía obligado el predisponente» ${ }^{63}$.

Añade además ORDUÑA MORENO que este hecho va en contra del derecho a la tutela judicial efectiva de los consumidores, quienes ven desvirtuadas sus pretensiones de solicitar la devolución íntegra de las cantidades indebidamente cobradas por la aplicación de unas cláusulas declaradas nulas.

En definitiva, la mayoría de la jurisprudencia y la doctrina se muestra partidaria de confirmar la declaración de nulidad por abusivas de aquellas cláusulas suelo no transparentes. Sin embargo, critican lo expuesto por el Supremo acerca de la no restitución íntegra de cantidades, apoyando su idea en el hecho de que la cláusula declarada nula de

abre los ojos y las mentes de las partes contratantes, pudiendo éstas indagar y esclarecer si las cláusulas suelo insertas en contratos de préstamo con tipo de interés variable, en principio lícitas, carecen de transparencia, no por oscuridad, sino por insuficiencia de información, en los términos indicados en el párrafo 225 de la sentencia» en relación con el F.D. $9^{\circ}$ : «...ignorancia que a partir de esta sentencia - 9 de mayo de 2013 - hace perder a la buena fe aquella naturaleza, pues una mínima diligencia permitía conocer las exigencias jurisprudenciales en materias propias del objeto social».

${ }^{63}$ Voto particular de Orduña Moreno a la STS 25 marzo 20I5, F.D. $7^{\circ}$. 
pleno derecho no encuentra título ninguno que lleve a justificar la retención y atribución de dichas cantidades a las entidades bancarias. Como podemos observar, el pronunciamiento de marzo de 2015 no introduce argumentos más allá de los expuestos en el de mayo de 20I3, por lo que no aclara las dudas ni contradicciones plasmadas en la jurisprudencia menor. Intenta esclarecer el criterio empleado para la no restitución, apelando al riesgo de trastornos socioeconómicos, seguridad jurídica y buena fe, aspectos todos estos criticados como he expuesto anteriormente.

Pues bien, como hemos podido ver, la decisión del Supremo de limitar la retroactividad ha sido enormemente criticada. Y existe además, gran incertidumbre entre los tribunales de instancia sobre la fecha a la que deben retrotraerse los efectos de la declaración de nulidad.

A modo de conclusión, diferenciamos por un lado, la consagración del doble control de transparencia, pudiendo resultar interesante en este sentido, plantearnos si este criterio es extrapolable a otro tipo de condiciones generales susceptibles de ser consideradas abusivas. Y diferenciamos, por otro lado, el problema de la limitación de la retroactividad, cuestión ésta que cuenta con más detractores que partidarios, como hemos podido ver. El Supremo de forma poco acertada, se aleja del tenor literal de la ley, sin justificación suficiente para ello, con la vulneración de principios de nuestro ordenamiento que ello conlleva (como pueden ser: el derecho a la tutela judicial efectiva o seguridad jurídica). Este hecho, unido al escaso esfuerzo argumentativo del Alto Tribunal, plantea dudas sobre si la solución por la que opta en su determinación es la más ajustada a la justicia de nuestro sistema jurídico. A este respecto, se deja abierto debate: «economía vs justicia» ¿es función de los tribunales salvaguardar la economía o impartir justicia aplicando la ley? 